\title{
Fad-like technology adoption as a social action
}

\section{Arthur P. Tomasino* and Jane Fedorowicz}

Bentley University, 175 Forest Street, Waltham, MA, 02452, USA

E-mail: atomasino@bentley.edu

E-mail: jfedorowicz@bentley.edu

*Corresponding author

\begin{abstract}
When technology adoption takes on fad-like characteristics, large swings in demand and expectations for the technology result. Companies can see revenues skyrocket, only to fall just as fast without understanding the dynamics of the consumer adoption decision process. In this paper, we present a model for fad-like technology adoption built upon Rogers' technology adoption lifecycle, to which we add the theory of information cascades and adopter thresholds. Adopter behaviour in each stage of the lifecycle may be individualistic or holistic, as suggested by the theories of Watkins and Durkheim. Macro (product) and micro (adopting user) level case analyses of the adoption of the Apple iPhoneTM illustrate the application of the model and the individual and holistic social actions of fad-like technology adoption. The paper closes with advice for consumer technology companies and a call for further study of industry and consumer factors that complicate the interpretation and prediction of adoption lifecycle activity.
\end{abstract}

Keywords: technology adoption; fad; diffusion; information cascade; individualism; holism; information technology; iPhone ${ }^{\mathrm{TM}}$.

Reference to this paper should be made as follows: Tomasino, A.P. and Fedorowicz, J. (2014) 'Fad-like technology adoption as a social action', Int. J. Information Systems and Management, Vol. 1, Nos. 1/2, pp.37-59.

Biographical notes: Arthur P. Tomasino is a Visiting Assistant Professor at Bentley University, Waltham, Massachusetts, USA. His $\mathrm{PhD}$ is also from Bentley University where his research focused on the complexity of information systems and the interaction of micro and macro-level activities to explain information system development. He uses complexity and chaos theory as the basis of his research and has applied these theories to analyse inter-organisational IT development in the field of public safety networks.

Jane Fedorowicz is the Chester B. Slade Professor of Accounting and Information Systems at Bentley University, Waltham, Massachusetts, USA. She holds a joint appointment in Bentley's Accountancy and Information and Process Management departments. Her MS and PhD in Systems Sciences were awarded by Carnegie Mellon University. Her recent research focuses on interorganisational design issues for public safety networks, including the role of social media in policing. She was named a Fellow of the Association for Information Systems in 2006. She currently serves as the President of the Association for Information Systems. 


\title{
1 Introduction
}

\author{
“... an iPhone...isn't just a cool gadget; it's a signifier of success.” \\ “...Apple fans...have an almost religious passion. It's hard to analyze this \\ phenomenon rationally." "From The Cult of Apple in China, Time, July 2, 2012, \\ page 44(Beech/Chengdu, 2012)]
}

Rapid advances across the spectrum of information technologies have spurred unprecedented technology adoption by both individuals and organisations. At times the adoption rate appears to be seemingly irrational, or fad-like, considering the short time to adopt and the magnitude of the adoption. Vendors introducing new products need to understand this social behaviour or they may be unable to meet consumer demand when the fad-like adoption starts, unable to adjust resources when the fad ceases and (perhaps worse) be severely hurt by a negative fad.

Studies from many domains document how people and organisations mimic behaviour or herd together for a wide range of reasons. Mimicry, herding, and fad-like behaviour may be encountered when selecting a mate (Gibson and Höglund, 1992), planning an organisation (Miller and Hartwick, 2002), or improving processes (DeToro and McCabe, 1997). Recent research identifies similar herding phenomenon among adopters of novel technologies, resulting in technology fads (Walden and Browne, 2009). In a similar vein, corporate managers' technology adoption decisions may also be based on fad or fashion (Baskerville and Myers, 2009; Ramiller et al., 2008). Although widely acknowledged to exist, uncertainty about what constitutes a technology fad still prevails (Wang, 2010). This paper adds to the understanding of fad-like technology adoption by examining the social actions of individuals when making the decision to adopt a new technology, and shows how individual action can lead to holistic fad-like activity.

Specifically we explain how fad-like technology adoption occurs at the micro, or individual, level and extend this to the macro, or holistic level. We extend previous research on either micro or macro fad-like technology adoption to include the interplay between both these levels showing the complexity of fad-like technology adoption and a better understanding of its mechanisms and behaviours for both theory and practice.

In this research, we define a technology fad as the rapid diffusion of a technology through a group of adopting individuals within a social network, sometimes followed by a similar and rapid de-adoption of the technology ${ }^{1}$. Previous research has shown that adoption of technology is dependent primarily on the technology's stage of development and with rapid new technology adoption derived from socially generated user expectations, whereas technology de-adoption may be slowed by user habit and inertia (Peters, 2009). Therefore, we expect very visible fad-like behaviour examples, stemming from social interaction, in the adoption of technology and concentrate our research in this area.

The uniqueness of our research is in the identification of micro-level patterns of behaviour, wherein adopter interactions centring on knowledge of adoption are sufficient to start and sustain fad-like adoption. Previous research maintains fad-like technology adoption requires higher levels of information exchange among potential adopters, incorporating beliefs about technology (Fichman, 2004), adopter reputation (Wang, 2010), or a learning process (Wang and Ramiller, 2009) to instigate a fad. We extend previous research by empirically showing how fad-like adoption triggered simply by knowledge of previous adoption leads to massive macro-level adoption. A key finding of 
our research is that the richness of adopter interactions is not as important as the interaction itself. In practical terms, new technology introduction should concentrate on quickly getting 'the story' out to potential adopters rather than spending time and efforts crafting detailed 'stories'.

In the next sections, we first define fad-like technology adoption and contrast this to existing literature. We adopt the concept of information cascades (Bikhchandani et al., 1992) as a basis for fad-like technology adoption and show how it relates to Roger's Technology Adoption Model (1962). We then present social action theory to explain how micro-level adopter interaction leads to holistic, macro-level fad-like adoption. We illustrate fad-like adoption by an analysis of individual level adoption through interactions captured on Facebook and in blogs (in China). The paper concludes with a discussion of the study implications, limitations, implications for practice, and guidance for follow on research.

\section{$2 \quad$ Fad-like technology adoption}

For fad-like technology adoption, the number of previous adoptions often drives the choice to adopt. That is, the value of the technology becomes more a function of the rate of adoption of the technology and less on the utility of the technology to the adopter, resulting in fad-like technology adoption that can be explained using technology adoption characteristics as follows.

- Individual units (the consumer) make a decision to adopt or not to adopt a technology. The unit can exist at any level, as a person, group (agency), company, or industry within a larger network of units.

- A unit's private information about the technology under consideration is available only to the individual unit.

- A social network of individual units all with a common purpose exists (for example, schools making a decision to adopt educational technology within a statewide association of schools). The network allows for communication and observation among all member individual units. The number of individual units within the network can be as small as three but will typically be much larger.

- An adoption rate measures the number of units adopting the new technology in a given time period. The rate typically will be very large and may show exponential growth in the number of individual units adopting the technology. A low adoption rate will indicate that fad-like technology adoption has not occurred.

Specifically, fad-like technology adoption occurs when individuals units within a social network exhibit a very high technology adoption rate irrespective of the private information they have regarding the technology. If prior to adoption all individuals are essentially identical (or identical with respect to the adoption) then the question emerges as to whether the adoption is an individual or group action. We examine both individualist and holistic (i.e., group) behaviours in the following section. 


\section{Alternative theories of fad-like behaviour}

Researchers often study fad-like behaviour holistically, that is, in relation to group dynamics and collective intelligence (Abrahamson, 1991). In early work, Trotter (1917) introduced the term 'herd behaviour' to describe the 'gregarious' behaviour of flocks or packs of animals. Beni and Wang (1989) presented the related concept of 'swarm intelligence', a collective intelligence exhibited by a group but not necessarily by the individual. Underlying many of these discussions are the perspectives of individualism, holism and information cascades.

The individualist view states that individuals add to their private information by observing the behaviour of others, so that a technology acquires a higher value simply by the knowledge that others have adopted. These decision makers 'herd together' and adopt the technology (Walden and Browne, 2009). The movement of the individual from a rational decision maker to a 'herd' member indicates a transition from individualist to holistic action.

Holistic actions are reflected in 'bandwagon pressures' (Abrahamson and Rosenkopf-Bartner, 1990) indicating that the number of units already employing the innovation compel the high rates of diffusion of innovation among individual units. Extensions to this idea (Abrahamson and Rosenkopf, 1997) include the effect of social networks on the units, showing that number of 'linkages' will have a great impact on the technology adoption rate.

The concept of information cascades (Bikhchandani et al., 1992) explains both the conforming behaviour of individuals and the rapid spread of new behaviours. An adoption process is defined whereby an individual unit's actions are a function of previous unit decisions in their network, regardless of the unit's private information, resulting in a phenomenon called an information cascade.

An important aspect of information cascades pertains to the initiation of the cascade. The holistic view of initiation incorporates environmental factors impressed on the individual unit. Network externalities and communications channels play a significant part in the formation of information cascades (Song and Walden, 2003). They model technology adoption as a function of positive feedback (a positive network externality) and information externalities (private information) where these factors tend to enforce the legitimacy of information cascades for decision making.

A more individualistic view comprises the examination of learning in social networks as an explanation for technology adoption behaviours. Gale and Kariv (2003) propose a model where the individual makes rational choices based only on the observed actions of other individuals and extracts information necessary for decisions from these actions. Information causes additional actions leading to an information cascade and rapid technology adoption (i.e., rapid learning). Similarly, Walden and Browne (2009) consider aspects of observational learning providing a robust information cascade model that shows individuals follow one another (or herd), but when an individual breaks from the herd it usually signifies important information that tends to reset the herding effect.

Although prior work is wide-ranging and extensive it focuses almost entirely on the operational aspects of fad-like technology adoption, explaining behaviour as a function of information flow, access to information, environmental measures, network externalities, and information cascades. This paper will re-examine the concept of fad-like technology adoption from the perspective of decisions made by individual units and the relation to their social network, while extending theories on fashion trends in IT management to the 
examination of individual action. Specifically, for fad-like technology adoption, it addresses the question, when do individual units appear to act alone and when do they appear to act collectively?

Roger's technology adoption bell curve (1962) model provides a starting point to illustrate the adoption of technology in seeking an answer to this question. The theory of information cascades augments Roger's model to extend it to fad-like adoption behaviour. We then augment these theories by covering the underlying behaviour of the individual unit from both holistic and individualist viewpoints, as the underlying mechanism for fad-like adoption. An analysis of the Apple iPhone ${ }^{\mathrm{TM}}$ at both the macro (product) and micro (individual adopter) levels provides a test case for the resulting theory of fad-like technology adoption. Illustration of the model with a specific product (iPhone $^{\mathrm{TM}}$ ) within a product class (smartphones) contributes to knowledge gained from technology adoption studies, including the broad-based technology introductions of EDI (Teo et al., 2003) or ATMs (Banker and Kauffman, 1988). A concluding section describes how an understanding of fad-like technology adoption can benefit technology companies and suggests future research directions.

\section{The technology adoption lifecycle model}

Rogers (1962) introduced a broadly accepted model to account for the spread of ideas and technology. His lifecycle model describes the adoption of a new product or innovation, according to the psychological characteristics of defined adopter groups. The model labels the first group of people to use a new product as innovators, followed by early adopters. Next come the early and late majority, and the last group to adopt a product are called laggards. A widely cited depiction of this lifecycle is presented in Figure 1.

Figure 1 The Roger's technology adoption lifecycle bell curve

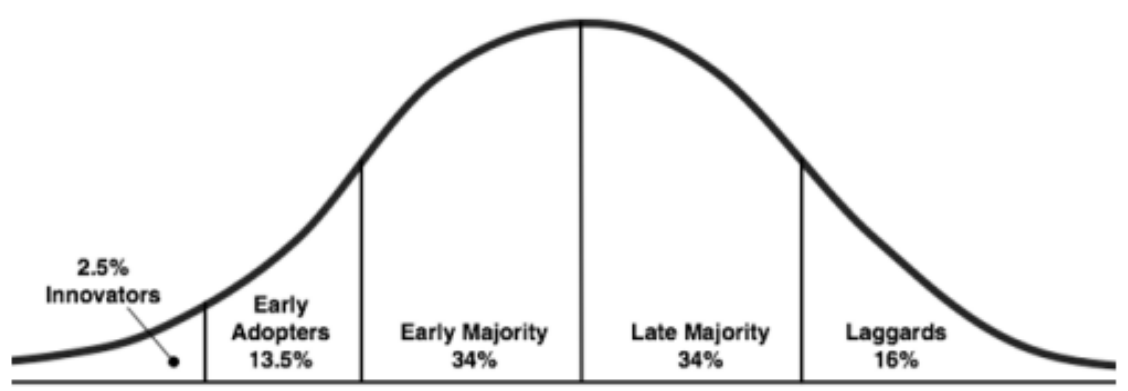

Source: Rogers (1962)

\subsection{Information cascades}

As defined in Bikhchandani et al. (1992, p.994),

"An informational cascade occurs when it is optimal for an individual, having observed the actions of those ahead of him, to follow the behavior of the preceding individual without regard to his own information." 
Adoption resembles a simple game where individuals make a technology decision based on private information they received regarding the technology and the decisions made by individuals preceding them (they only know the decision and must infer the private information of the preceding individual). Holistically, individuals are game players following a strict set of rules based on binary inputs of prior decision makers. This results in fad-like behaviour because once the information cascade starts all subsequent decisions are made disregarding any information outside the system (each individual's private information is disregarded).

Although useful for modelling fad-like technology adoption, this model provides only a binary depiction of an individual unit's decision process. As Walden and Browne (2009) state, a vast amount of information available to the individual unit can be utilised to make an adoption decision. Therefore modelling the information cascade with a simplistic rule lacks face validity because it does not approach the complexity of real world adoption decisions.

Another view on adoption decision modelling incorporates the concept of a threshold effect (Valente, 1996). In fad-like technology adoption, an individual unit, based on their personal information and position within their social network, will establish a threshold of previous adoptions before they will adopt the technology. Once the adopter threshold is met or exceeded the individual unit adopts the technology disregarding any personal information relevant to the decision to adopt. Therefore, the adopter threshold defines the condition when the individual unit makes decisions based only on other individual units and thus exhibits fad-like technology adoption behaviour.

\subsection{Fad-like technology adoption model}

Considering the theory of information cascades and applying the adopter threshold criteria, Roger's technology adoption individual unit descriptions can be modified to reflect fad-like technology adoption as follows.

- Innovators - as Demirci and Ersoy (2008) have shown these first adopter individual units tend to be innovators and have high optimism towards technology. Their adopter threshold is irrelevant as there are potentially no previous adopters and they base their decision totally on their private information and individual characteristics.

- Early adopters - include individual units that exhibit the characteristics of innovators but with very low adopter thresholds. They adopt the technology after only a very few innovators have already adopted and by definition, have a low adopter threshold. They may be influenced by other social influences that are not directly related to adopter thresholds, such as 'prestige' (Tscherning and Mathiassen, 2010).

- Early majority - these individual units have higher adopter thresholds than early innovators but since more previous adoptions have occurred more of these units have their threshold met to adopt.

Technology adoption grows based on individual units obtaining information on the increasing numbers of previous adopters. With the increase in numbers of adopters, more individual units meet their adoption threshold and start adopting the technology. As a result a very high adoption rate is achieved based mainly on previous adopters (Bikhchandani et al., 1992). 
Adoption starts to ebb as the lifecycle reaches the late majority and laggard individual units, defined as follows.

- Late majority - these units will have high adopter thresholds. As a result they appear to adopt only when almost everyone else has already adopted.

- Laggards - these units have extremely high adoption thresholds. Their threshold is most likely never met.

The addition of information cascades and adopter threshold effects modifies the shape of the Roger's Technology Adoption Lifecycle Curve. Due to the multiplicative effects in the innovator and early adopter stages there is a very high initial adoption rate followed by a decline in adoptions. Abrahamson and Rosenkopf-Bartner (1990) validate these results by simulation of a similar model. Figure 2 depicts the resulting fad-like technology adoption life-cycle curve.

Figure 2 Fad-like technology adoption lifecycle

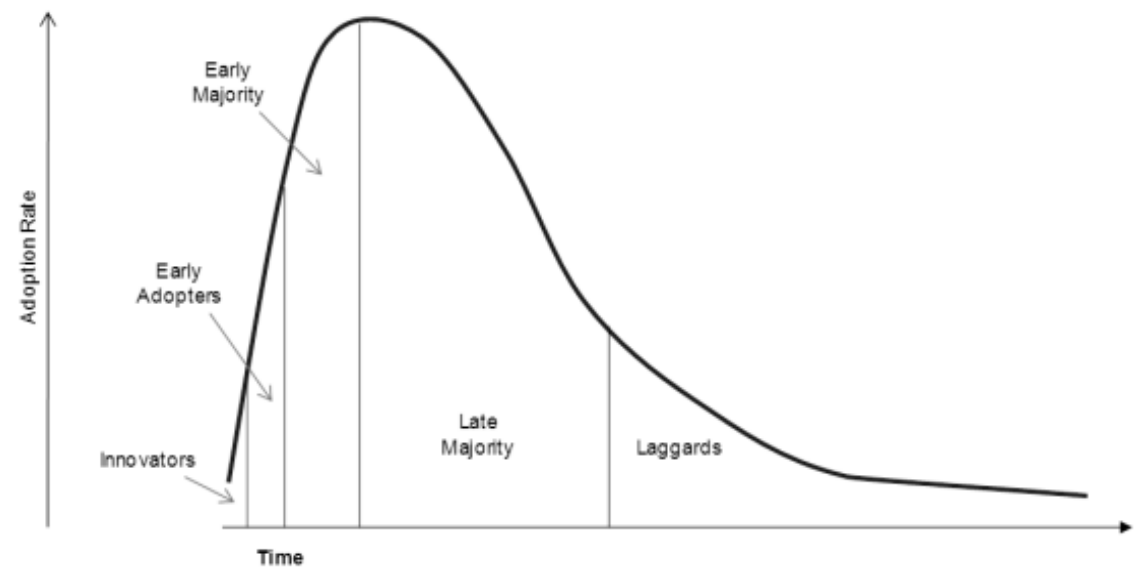

\section{Understanding social action}

Although the fad-like technology adoption lifecycle curve shows rapid adoption rates it does not offer an explanation for the rate. The resulting curve is a left-skewed Roger's technology adoption lifecycle curve that can be explained by our fad-like technology adoption model. As stated previously, this model represents a sound operational model for examining adoption rates, but it fails to look for an explanation for the social actions. To apply this model and understand the complexities of fad-like technology adoption a full understanding of when, and if, individual units act in a holistic or individual manner is needed.

\subsection{Individualism and fad-like technology adoption behaviour}

Watkins' (1957, p.114) work on Methodological Individualism supplies a starting point for viewing fad-like technology adoption as an individualist behaviour: 
"...members of some social system (that is, a collection of people whose activities disturb and influence each other) mutually adjust themselves to situations created by others in a way which, without direction from above, conduces to the equilibrium or preservation or development of the system."

He states that individual action derives from an individual's disposition and situation. Individuals in a certain situation and with similar disposition will generate a regularity or process.

When applied to fad-like technology adoption, Watkins' perspective describes both innovators and laggards as exhibiting individual predispositions (Demirci and Ersoy, 2008). Each group makes the decision to adopt a technology (or not adopt) in opposition to the actions of their social network. The innovator makes the adoption decision because very little previous adoption has occurred in the social network. In the case of the laggard the decision to not adopt runs contrary to the fact that most of their social network has already adopted the technology.

Thus, the innovator and laggard, as individual units, make technology adoption decisions as singular agents (Gilbert, 1990) predisposed to adopting or not adopting the technology. The predisposition is based on private knowledge they receive about the technology. These actors enact the role of an innovator or laggard. They exhibit certain role characteristics (Demirci and Ersoy, 2008) that cause unique action when interacting within their social network. Therefore, from an individualistic viewpoint, the initiation of the information cascade is a bottom-up event caused by the actions of individuals in unique circumstances.

\subsection{Holism and fad-like technology adoption}

A holistic viewpoint of fad-like technology adoption would consider this phenomenon as a group practice [Durkheim, (1938), p.435],

"It is, however, the collective aspects of the beliefs, tendencies, and practices of a group that characterize social phenomena. As for the forms that the collective states assume when refracted in the individual, these are things of another sort."

and rapid adoption of a technology as a form of collective agreement.

Similarly information cascades can be viewed as the rules that the system applies to individuals. Rules hold Individuals units accountable (Hollis, 1934), in this case, the rule of information cascades. Each unit, although having private information relevant to their adoption decision, will still decide based on collective rules.

The analysis becomes more complicated when adopter thresholds of the individual units are added to the holistic view. Information cascades fit Durkheim's tendencies and practices of a group, but it is the adopter threshold for the technology that defines the collective beliefs. Although an individual unit may act counter to its personal information if there is no adopter threshold (for the technology adoption), no fad-like action can proceed. In fad-like technology adoption some large number of individual units with surmountable adopter thresholds must all share a collective belief that, when their threshold is met, they will adopt the technology irrespective of any other information.

Fad-like technology adoption is then viewed as a game playing system. The early adopter, early majority and late majority individual units define a system that societal units work within to make technology adoption decisions. The system, to the individual unit, looks like a game that has a rule specifying the adoption decision as a function of 
previous decisions and private information. During the early adopter, early majority and late majority stages of the technology adoption lifecycle, fad-like technology adoption portrays an extreme holistic view with each individual unit acting within a prescribed set of rules. The adopter threshold, which would appear to be very much an individual trait can be viewed as just another rule when considering that large numbers of individual units must have surmountable thresholds.

This somewhat harsh view can be moderated by looking at the individual unit as containing an unpredictable behaviour that adds to the holistic model (Kincaid, 1986). Kincaid states that a full explanation of a social event cannot be explained without involving individuals. Within fad-like technology adoption he would see the adopter threshold or the unit that breaks from the collective behaviour to be not a rule of the extent of private information, as do Walden and Browne (2009), but rather an unpredictable action of an individual.

Therefore the early and late stages of the fad-like technology adoption lifecycle can be seen as predominately actions defined by the individual. In the middle stages, during which the information cascade is present, actions are dominated by holistic rules but there is always an element of individual action that can moderate the adoption rate within the information cascade or in the extreme terminate the cascade. The next section provides examples of how this plays out in the consumer marketplace.

\section{Macro and micro level case examples}

Fad-like technology adoption can occur in many different settings and with many different technologies. We apply our analysis of fad-like adoption to consumer behaviour regarding smartphones. We identify the holistic aspects of fad-like smartphone adoption by examining the Apple iPhone $^{\mathrm{TM}}$ using four separate analyses with each analysis' result adding to prior analyses. The first two examples describe iPhone ${ }^{\mathrm{TM}}$ at the product, or macro level. The second two are micro-level examples, illustrating the behaviour of individual adopters.

Certainly the continued popularity and use of the iPhone ${ }^{\mathrm{TM}}$ does not classify the product as a fad. We choose the iPhone ${ }^{\mathrm{TM}}$ because the introduction of each new version is followed by unprecedented rapid adoption by users. Therefore, it fits our area of analysis, namely technology adoption, and potentially exhibits fad-like behaviours based on its rapid adoption.

First we analyse secondary data comprising a review of extant research and industry expert opinion to characterise the condition and process for fad-like iPhone ${ }^{\mathrm{TM}}$ adoption. A second analysis uses iPhone ${ }^{\mathrm{TM}}$ sales data and statistics to identify rapid adoption of the iPhone $^{\mathrm{TM}}$ as a condition for fad-like adoption. A third analysis illustrates individual behaviour by a single case of Apple iPhone ${ }^{\mathrm{TM}}$ adoption captured via an individual's use of a social networking application. Finally, we provide interpretive analysis of consumer blogs entries in the Chinese smartphone market. The intent of these analyses is to demonstrate that fad-like adoption provides a viable explanation for iPhone ${ }^{\mathrm{TM}}$ adoption.

\section{1 iPhone $^{T M}$ adoption}

The iPhone ${ }^{\mathrm{TM}}$ is an advanced communications device incorporating a mobile phone, a widescreen iPod ${ }^{\circledR}$ with touch controls, and internet communications. Introduced in June, 
2007, by the end 2008 the product was marketed in over 70 countries accounting for $\$ 1.8$ billion in net annual sales (Apple, 2008), making this an ideal product with which to demonstrate fad-like behaviour.

When first introduced, consumers were "already lining up in front of the Apple store in downtown Manhattan - a full three days in advance" (Block, 2007). Irrational adoption of the new product was not a surprise, as belatedly observed by Microsoft CEO Steve Balmer.

\begin{abstract}
"When the iPhone launched with a $\$ 500$ price, Microsoft CEO Steve Ballmer said his first reaction was "that is the most expensive phone in the world and it doesn't appeal to business customers because it doesn't have a keyboard." Later he said, "it may sell very well." [Needle, (2009), p.2]
\end{abstract}

Previous research shows that the iPhone ${ }^{\mathrm{TM}}$ was first adopted for many reasons, namely, consumer devotion (defined as those with intense loyalty to the Apple brand) social use (those wishing to establish social relationships as innovative users), pioneering owners of this new technology, personal fit and technology evaluations (Arruda-Filho et al., 2010; Demirci and Ersoy, 2008). These studies show that the conditions for fad-like technology adoption existed, exhibiting the fad-like adoption criteria noted here:

- Individuals make the decision to adopt the technology (purchase the $\mathrm{iPhone} \mathrm{T}^{\mathrm{TM}}$ ).

- The individual exists within a social network defined as smartphone users.

Communication within the network occurs through mass media or the internet.

- The individual has private information regarding the technology which is based on their personal needs for the technology. Information regarding the technology is common, but the fit of the technology to the user is private.

- The adoption rate is very high. In the first three days after introduction the original iPhone $^{\mathrm{TM}}$, iPhone ${ }^{\mathrm{TM}} 3 \mathrm{G}$, and $\mathrm{iPhone}^{\mathrm{TM}} 4$ sold $270,000,1$ million units, and1.7 million units, respectively! (Block, 2007; Graham, 2010b; Krazit, 2008). These astonishing adoption rates were topped by the iPhone ${ }^{\mathrm{TM}} 4 \mathrm{~S}$, as Apple reported pre-selling over one million phones and selling over 4 million units in the first week of availability (Bedigian, 2012).

\title{
6.2 Macro adoption behaviour
}

\subsubsection{Example 1}

Figure 3 shows the adoption rate for the iPhone ${ }^{\mathrm{TM}}$, in comparison to previous successful product introductions. As can be seen, the product has a very high adoption rate relative to other popular technologies, such as Netscape and AOL. With respect to Roger's technology adoption model, it appears the iPhone ${ }^{\mathrm{TM}}$ progressed from the innovator stage to the early adopter then late majority stage during the initial introduction of the device suggesting the existence of an adoption factor that did not exist or was not as prominent for Netscape and AOL. 
Figure 3 iPhone ${ }^{\mathrm{TM}}$ quarterly subscribers since launch

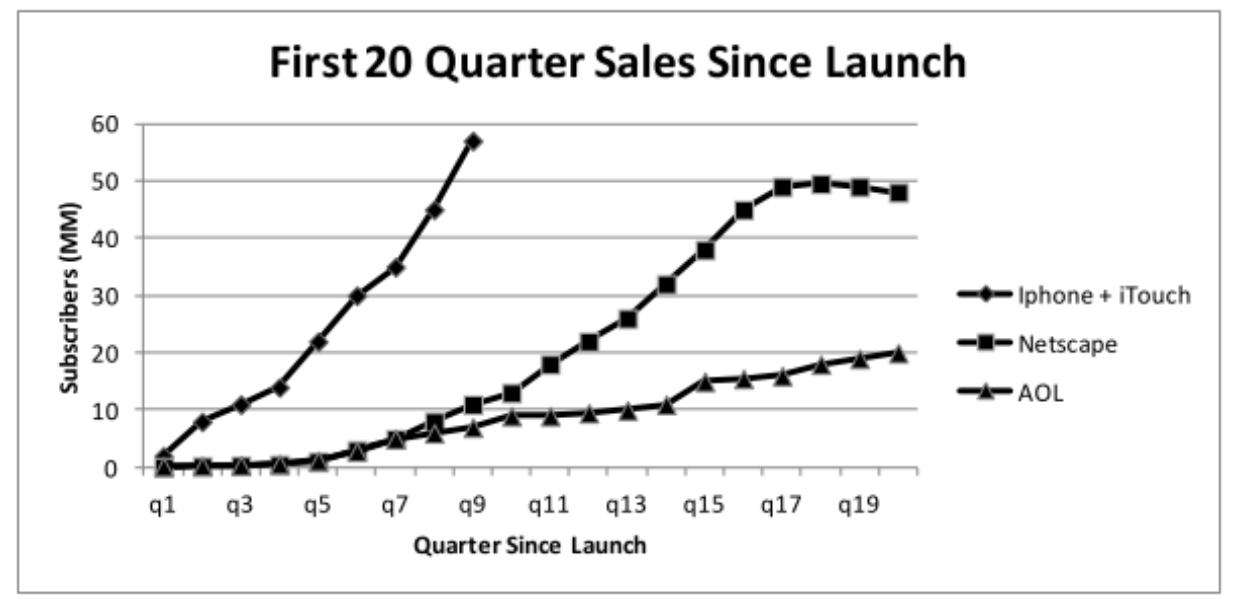

Figure 4 compares iPhone $^{\mathrm{TM}}$ purchase rates for the beginning of each product introduction (i.e., the first three days' average sales) and for each fiscal quarter (average sales). Note the very high adoption rate at introduction of the different versions of the iPhone $^{\mathrm{TM}}$, three to five times higher than the corresponding quarterly rates. This indicates a rapid adoption occurring with the introduction of each version.

Figure 4 iPhone $^{\mathrm{TM}}$ daily sales in first three days after introduction versus average daily quarter sales

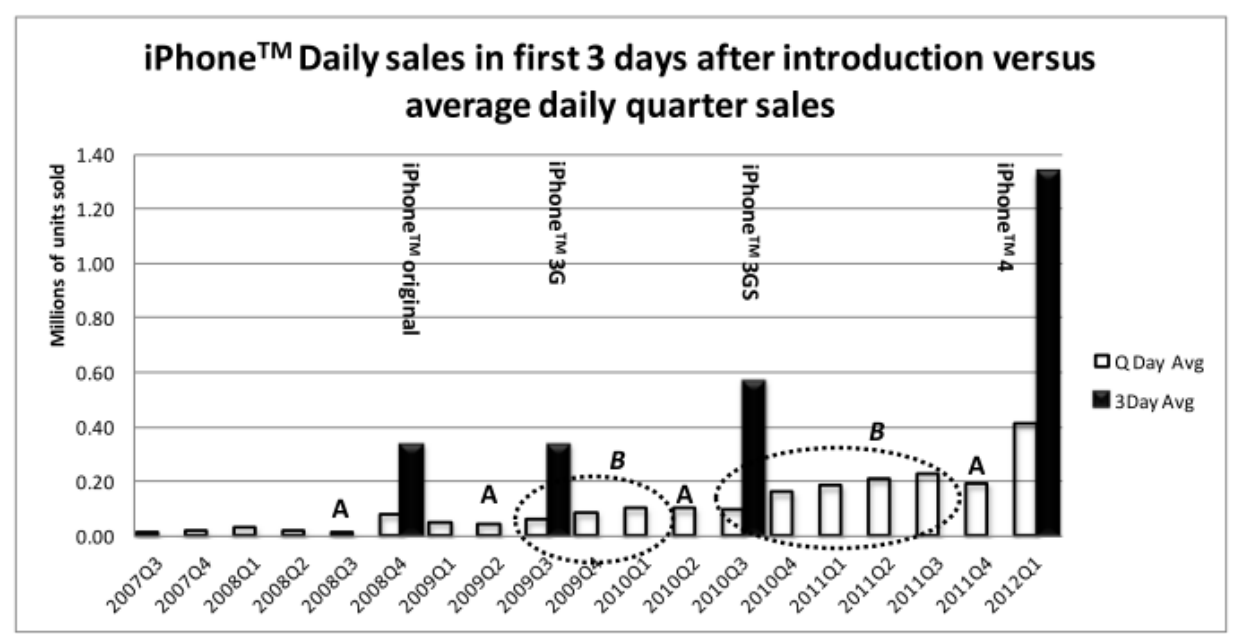

Industry experts explain high adoption rates as a situation where a large number of innovators purchase the product based on their private information (technical and utility data). At each release, Apple manipulates adopter thresholds to create a scenario where adoption decisions are made prior to the actual release of the device. As stated by industry analyst Mike Schramm (2009), 
"So the real story here isn't necessarily that Apple masterfully created a smartphone that revolutionized the industry and made tons of money doing it, but that they coordinated a hype machine that marched to their tune whenever they wanted. There's nothing like the excitement and hype that shoots up around a big Apple event. The iPhone is a feat of engineering in itself, but the hype machine behind it is pretty well-built, too."

Viewed from the perspective of individualism and holism (for fad-like technology adoption) Apple's marketing efforts demonstrate two effects. First they reduce the individual's decision thresholds by generation of product excitement, and cause an information cascade prior to introduction of the product. Second, by pre-introducing the product they create private information that will cause higher decision thresholds. These thresholds are not easily exceeded and thwart any negative information cascades that may begin at actual introduction. Individuals that feel the product does not meet expectations will be overwhelmed by the numbers that are adopting, thus countering any negative cascades. Prior to product introduction the vendor manipulates the individual.

Figure 5 iPhone $^{\mathrm{TM}}$ fiscal quarter and annual unit sales

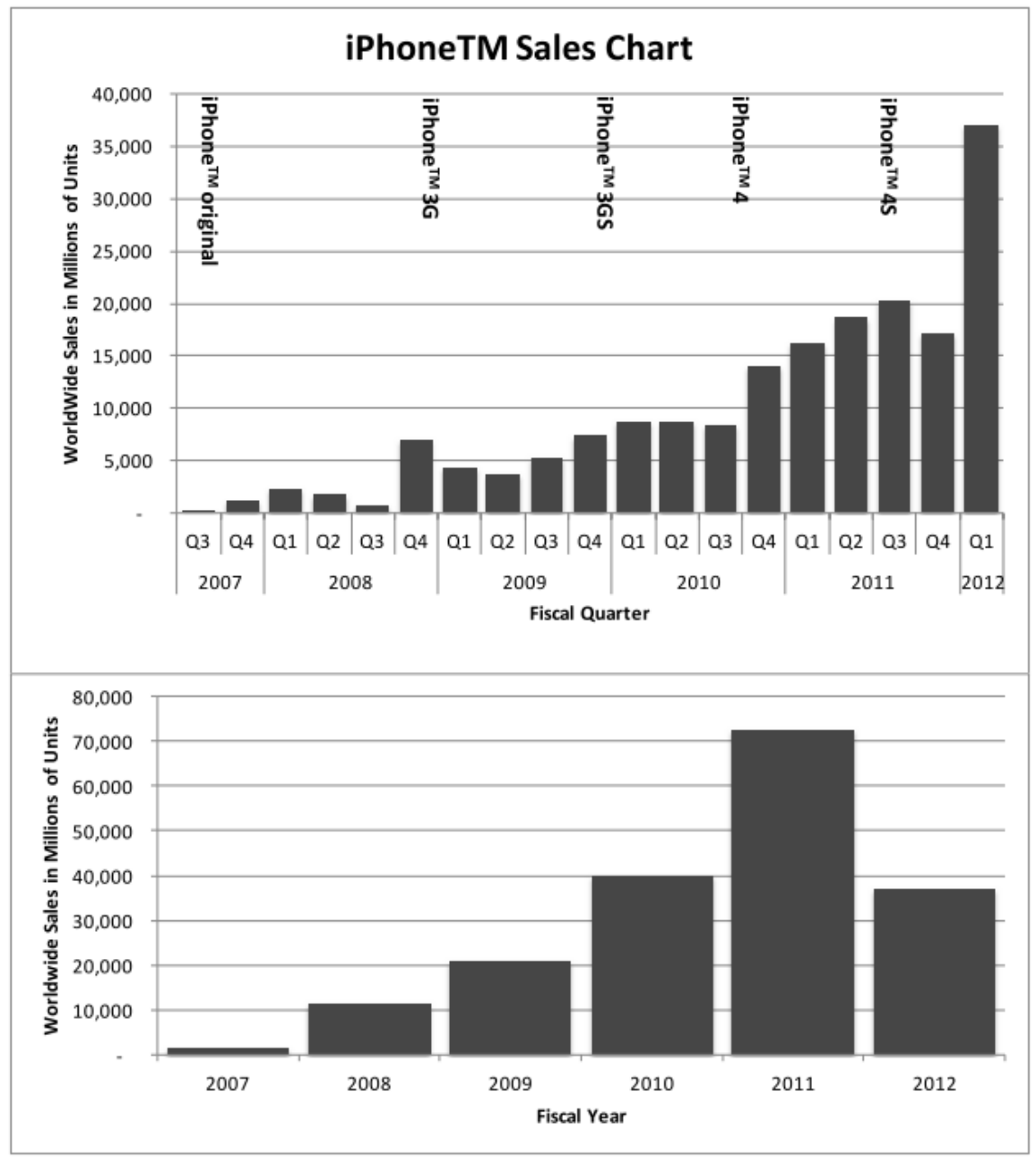


At product release the holistic nature of fad-like technology adoption takes over and the adoption rate soars. Individual units buy-based solely by rule, driven by the previous adoption of other units by creating a sales environment where private information becomes almost irrelevant, iPhone ${ }^{\mathrm{TM}}$ adoption follows holistic rules and individual behaviours do not come into play.

\subsubsection{Example 2}

A closer examination of the unit sales of the iPhone ${ }^{\mathrm{TM}}$ supports the notion that adoption is holistic in nature. Figure 5 shows the adoption of the iPhone ${ }^{\mathrm{TM}}$ for the first four different versions of the technology. In each case a rapid adoption of the iPhone ${ }^{\mathrm{TM}}$ occurs at introduction, indicating an information cascade. Prior to introduction of each new version, Apple reduces inventory of the existing device to create demand for the new device. By controlling demand for the existing device they re-introduce excitement for the new device that once again lowers decision thresholds and initiates a new information cascade (Graham, 2010a). Similarly, by managing the release of technical information they can control individuals with higher decision thresholds and thwart negative cascades.

Although the overall adoption cycle of the iPhone ${ }^{\mathrm{TM}}$ can be viewed as holistic, it still exhibits individual adoption action in its earliest stages. Apple creates fad-like technology adoption for the iPhone ${ }^{\mathrm{TM}}$ by creating a highly functional device that appeals to innovators and a cult of celebrity surrounding those who first adopt the iPhone ${ }^{\mathrm{TM}}$, so that individual units must have the device (Kunz et al., 2011; Murphy, 2008). Thus, the adoption rate for the $\mathrm{iPhone}^{\mathrm{TM}}$, upon announcement, almost instantaneously moves into the early adopter and early majority stages of the fad-like technology adoption lifecycle.

\subsection{Micro level adoption behaviour}

\subsubsection{Example 3}

We complement the macro-level analysis of iPhone ${ }^{\mathrm{TM}}$ adoption with two illustrative examples of how fad-like adoption occurs at the individual level of analysis. In this first example, we observed a request for advice on to purchase a smartphone made by an individual consumer over Facebook ${ }^{\mathrm{TM}}$.

Tables 1 and 2 contain transcripts of real interchanges posted on the Facebook ${ }^{\mathrm{TM}}$ Wall of an individual from the US we call 'BG'. The authors did not participate in the interchange in any way prior to or during the postings. BG was not aware of the authors' interest until after all postings had been made to her Wall in response to her real request for information. All names have been removed to preserve the privacy of BG and her friends. Other than anonymisation, the contents of the interchanges have not been altered in this transcription. All of these postings occurred in 2010 and are provided with BG's permission.

Table 1 details a series of communications among Facebook ${ }^{\mathrm{TM}}$ friends over a one day period. The initiator of the messages (BG) starts the conversation by asking for advice on the purchase of a new cell phone. BG receives comments regarding phones, travels to a store to try the phones, then returns for a second round of advice. BG eventually decides to purchase the iPhone ${ }^{\mathrm{TM}}$. 
Table 1 Transcript of a Facebook ${ }^{\mathrm{TM}}$ communication regarding the adoption of the iPhone $^{\mathrm{TM}}$

\begin{tabular}{|c|c|c|}
\hline Person & Time & Message \\
\hline$B G$ & $9: 24 a m$ & $\begin{array}{l}\text { I need a new phone. I've had a Blackberry } 8830 \text { through Verizon for } 2 \\
1 / 2 \text { years and have really liked it but its on the fritz now. Any } \\
\text { suggestions out there on what I should look at and why? }\end{array}$ \\
\hline Friend_1 & 9:31am & iPhone need I say more? \\
\hline Friend_2 & 9:23am & $\begin{array}{l}\text { A friend of mine has the Palm Pre. Its pretty cool. I heard the iPhone } \\
\text { was going to be on Verizon by the end of the year if you can wait that } \\
\text { long. }\end{array}$ \\
\hline Friend_3 & 9:44am & $\begin{array}{l}\text { I have a couple of friends with the Droid who are very happy with it. } \\
\text { I'm and iPhone kind of gal myself. }\end{array}$ \\
\hline Friend_3 & 9:49am & $\begin{array}{l}\text { And if you stick with a Blackberry there are several newer ones you } \\
\text { might like. :) }\end{array}$ \\
\hline Friend_4 & 10:02am & $\begin{array}{l}\text { I like my BB too, but the iPhone rocks! It has so many capabilities } \\
\text { beyond a phone and email. }\end{array}$ \\
\hline Friend_5 & 10:09am & iPhone all the way! Ull loove it:) \\
\hline Friend_6 & 10:31am & I'm having an affair with my iPhone, I love it so... \\
\hline Friend_7 & 10:49am & I love my BB World Tour \\
\hline Friend_8 & 11:04am & iPhone. Easily the best. \\
\hline BG & 11:19am & $\begin{array}{l}\text { Thanks for all your input everyone. I am definitely debating between the } \\
\text { iPhone, Droid and a newer Blackberry. Does anyone care to admit any } \\
\text { problems they have had with their phones, or what they wish their } \\
\text { phones did that it doesn't do (aside from make you dinner)? }\end{array}$ \\
\hline Friend_8 & $11: 27 \mathrm{am}$ & $\begin{array}{l}\text { I wish my iPhone had video so I could film the craziness of my kids. } \\
\text { The phone is OK - not great bu not bad. Otherwise I think its great. }\end{array}$ \\
\hline Friend_7 & $12: 01 \mathrm{pm}$ & $\begin{array}{l}\text { The new BB World Tour has both video and } 3.2 \text { megapixel camaera... as } \\
\text { I said before, I love it! }\end{array}$ \\
\hline Friend_9 & $12: 10 \mathrm{pm}$ & $\begin{array}{l}\text { There is an iPhone video application available now. My vote goes for } \\
\text { iPhone as well. Definitely a lot more durable than I imagined, my } \\
\text { iPhone has gone through hell and still works. It has been in the pool, } \\
\text { cracked, dropped numerous times so it has taken quite a beating. I refuse } \\
\text { to get a } 3 \mathrm{G} \text { until this phone has given me all its got. }\end{array}$ \\
\hline Friend_10 & $12: 22 \mathrm{pm}$ & iPhone baby!!!!! Although my friend likes his new BB. \\
\hline Friend_11 & $12: 45 \mathrm{pm}$ & $\begin{array}{l}\text { I have the iPhone and the new BB curve with the touch pad instead of } \\
\text { the roller bar. (I know.... one's for work, one's for play). If you stay } \\
\text { with BB the touch pad is totally the way to go. If you want I have my } \\
\text { old (less than a year) BB curve w/ verizon you can have if you want to } \\
\text { hold out until they get the iPhone. BBs are way better on e-mail, but } \\
\text { iPhone is wal better w/ fun stuff like apps and internet. }\end{array}$ \\
\hline Friend_12 & $1: 52 \mathrm{pm}$ & I have the BB Tour and I love it. \\
\hline Friend_13 & $2: 10 \mathrm{pm}$ & $\begin{array}{l}\text { I have the BB Storm. Some people don't like it, but I haven't had any } \\
\text { issues. I like the qwerty keyboard! }\end{array}$ \\
\hline BG & $2: 17 \mathrm{pm}$ & $\begin{array}{l}\text { Thanks for the additional info peeps! I think the lack of qwerty } \\
\text { keyboard on iPhone is my biggest issues with picking it. Nothing's ruled } \\
\text { out though. I'm going to play with my narrowed down list now. }\end{array}$ \\
\hline
\end{tabular}


Table 1 Transcript of a Facebook ${ }^{\mathrm{TM}}$ communication regarding the adoption of the iPhone $^{\mathrm{TM}}$ (continued)

\begin{tabular}{|c|c|c|}
\hline Person & Time & Message \\
\hline \multicolumn{3}{|c|}{$B G$ goes phone shopping and returns later in the day. } \\
\hline BG & $6: 16 \mathrm{pm}$ & $\begin{array}{l}\text { I looked at phones today. Didn't like the way the Droid felt or the } \\
\text { keyboard. The store couldn't get either of their Palm Pre's to work (bad } \\
\text { sign). I liked the BB Storm bettwr than the Tour (I think). But, right now, } \\
\text { I'm leaning towards the iPhone. Yes, that's where I'm leaning. Will } \\
\text { sleep on it. Thanks for all your help FB friends }\end{array}$ \\
\hline Friend_3 & $6: 18 \mathrm{pm}$ & $\begin{array}{l}\text { Had I known the iPhone was a consideration for you (I thought you } \\
\text { wanted to stay with Verizon) I wouldn't have even mentioned the others } \\
\text { 'cause there's no comparison. You will LOVE the iPhone! }\end{array}$ \\
\hline BG & $6: 27 \mathrm{pm}$ & $\begin{array}{l}\text { As I said I currently have Verizon and their discounts on phones are } \\
\text { very good for returning customers which is still a small draw for staying } \\
\text { with them. AT\&T has a } 15 \% \text { discount on service so if I go with the } \\
\text { iPhone I will be adding on to my husband's plan and will make that } \\
\text { much cheaper. I'm up for a change. }\end{array}$ \\
\hline Friend_14 & $6: 56 \mathrm{pm}$ & $\begin{array}{l}\text { I switched from Verizon to an iPhone in November. Beyond glad that I } \\
\text { did. }\end{array}$ \\
\hline Friend_3 & $6: 57 \mathrm{pm}$ & I made the switch in May and haven't looked back. :) \\
\hline Friend_14 & $6: 58 \mathrm{pm}$ & So basically the iPhone has my approval! \\
\hline BG & 7:00pm & $\begin{array}{l}\text { Haha! So it seems! Glad to hear from people who have switched and are } \\
\text { happy. I've been with Verizon for so long I feel like I'm breaking up } \\
\text { with a boyfriend! }\end{array}$ \\
\hline Friend_15 & $7: 05 \mathrm{pm}$ & $\begin{array}{l}\text { Just in case you need some more influence. I love the iPhone and use it } \\
\text { more than my computer. }\end{array}$ \\
\hline BG & 7:08pm & $\begin{array}{l}\text { Now I'm beginning to feel like a bandwagon fan and ins't in my } \\
\text { vocabulary! But hopefully if I do chose the iPhone it won't fail me like } \\
\text { the Bills....or Orioles! }\end{array}$ \\
\hline Friend_16 & $9: 48 \mathrm{pm}$ & $\begin{array}{l}\text { There is a new iPhone coming out in June, I think. I have } 3 \text { gs and I love } \\
\text { it!! I am actually addicted to it. I have not turned on my computer in } \\
\text { weeks. Go iPhone. }\end{array}$ \\
\hline BG & $10: 47 \mathrm{pm}$ & Thanks. I think I'm convinced. \\
\hline
\end{tabular}

The speed with which information passes between the individual unit and those advising her is remarkable, and shows how social networking tools enhance the rate and cost of the exchange of information among agents and actors, compressing the collection and response of fad-related input into a single day, in this case. The rapidity with which BG seeks, obtains, and acts upon advice, and the sheer number of responses received illustrate how subjective norms affect intention to adopt a new technology ( $\mathrm{Li}$ et al., 2008).

A close examination of the communications shows very little discussion regarding the actual features of the iPhone ${ }^{\mathrm{TM}}$. Most of the information BG obtains is not device specific but rather the number of other individual units (friends) who have already adopted the iPhone $^{\mathrm{TM}}$. At one point BG literally admits to falling on the iPhone ${ }^{\mathrm{TM}}$ bandwagon! $\mathrm{BG}$ disregards even private information received from the store visit (except possibly the negative information on the iPhone ${ }^{\mathrm{TM}}$ competitor phone) and, by rule, BG makes the 
adoption decision based on other units' adoption, solely. This exemplifies the application of holism to fad-like technology adoption.

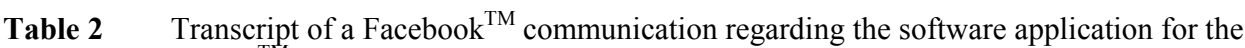
iPhone $^{\mathrm{TM}}$

\begin{tabular}{|c|c|c|}
\hline Person & Time & Message \\
\hline \multicolumn{3}{|c|}{ A month later, BG announces she has an iPhone } \\
\hline BG & $6: 50 \mathrm{pm}$ & $\begin{array}{l}\text { My husband gave me an iPhone for my birthday... } \\
\text { what a wonderful guy! I mean I like the vacuum cleaner he gave me last } \\
\text { year and all but somehow it's just not the same :-) }\end{array}$ \\
\hline Friend_3 & $6: 52 \mathrm{pm}$ & $\begin{array}{l}\text { I think an iPhone would win out over a vacuum } 9 \text { times out of } 10 \text {. For } \\
\text { me, } 10 \text { times out of } 10 \text { because we don't have carpet. LOL }\end{array}$ \\
\hline Friend_6 & $6: 52 \mathrm{pm}$ & $\begin{array}{l}\text { Awesome! Love my iPhone! The mapping and all the game apps are } \\
\text { awesome! }\end{array}$ \\
\hline Friend_17 & $7: 49 \mathrm{pm}$ & thats cause he knows you'll use the iPhone more than the vacuum...DOH! \\
\hline Friend_18 & $8: 21 \mathrm{pm}$ & $\begin{array}{l}\text { hahaha im sorry BG but that was funny. thats cool tho i hope } u \text { had a nice } \\
\text { night. }\end{array}$ \\
\hline BG & $12: 58 \mathrm{am}$ & $\begin{array}{l}\text { What are some cool (free preferably) apps for my iPhone that I need to } \\
\text { get folks? }\end{array}$ \\
\hline Friend_19 & 1:07am & $\begin{array}{l}\text { Stanza, classics, google earth, scrabble }(\$ 5), \text { msnbc, nyt crosswords, } \\
\text { bing, amazon, sudoku, relax free, mashable, twitterific. And of course } \\
\text { facebook! }\end{array}$ \\
\hline Friend_16 & 1:13am & $\begin{array}{l}\text { Solitaire, black Jack, doodle draw, air hockey (can be played as a } 1 \text { or } 2 \\
\text { player), sudako, war, traffic jam, and anything that is listed under the top } \\
\text { free. If you are looking to buy something: Rock Band is fun and keeps } \\
\text { me busy as does Life (the board game). I think these are both } \$ 5 \text {. Have } \\
\text { fun and congratulations on your present!!! }\end{array}$ \\
\hline Friend_16 & $1: 14 \mathrm{am}$ & Sorry, Sudoku \\
\hline Friend_20 & 1:07am & $\begin{array}{l}\text { Oooo, and SimonClassic (just like the old Simon game). Hubby says Tap } \\
\text { Tap Revenge, too. Have fun!!!! }\end{array}$ \\
\hline Friend_6 & $1: 28 \mathrm{am}$ & $\begin{array}{l}\text { shazam, Geared (maybe } 1.99 \text {, but worth it), Gmail, Facebook, USA } \\
\text { Today Crosswords (4.99), so many so good. }\end{array}$ \\
\hline BG & $1: 55 \mathrm{am}$ & $\begin{array}{l}\text { Thanks ladies! Looks like I'm going to be busy! any reason to get the } \\
\text { gmail app if my gmail account goes directly into my messages location? }\end{array}$ \\
\hline Friend_6 & 1:58am & $\begin{array}{l}\text { ummm...not sure what messages location is, but I have it to check my } \\
\text { gmail easily. }\end{array}$ \\
\hline BG & 2:01am & $\begin{array}{l}\text { I guess I didn't mean messages (which is where my text messages are } \\
\text { located) but I meant the mail button on the phone - where all of my } \\
\text { emails go to. Not a big deal... I'll see what I can figure out. Thanks! }\end{array}$ \\
\hline Friend_21 & $2: 23 \mathrm{am}$ & $\begin{array}{l}\text { Ifarkle... Scrabble (hell yes)... Pandora... Bejeweled } 2 \ldots \text { Cubes... Speed... } \\
\text { Moron test (freaking great!)... collapse. That should keep you busy (and I } \\
\text { still have } 5 \text { more pages I haven't peeked at yet) lol }\end{array}$ \\
\hline Friend_6 & 3:18am & Words with Friends \\
\hline Friend_1 & $6: 24 \mathrm{am}$ & Word warp, shazam \\
\hline Friend_1 & 6:26am & Urbanspoon \\
\hline Friend_17 & $10: 27 \mathrm{am}$ & Linkedin. Bump. Weatherchannel. Fandango. Scramble2. Crack the code. \\
\hline Friend_22 & $10: 30 \mathrm{am}$ & and of course, the Win 7 app that makes it run as smooth as windows! \\
\hline
\end{tabular}


Fad-like technology adoption occurs not only for the iPhone $^{\mathrm{TM}}$, but further communications show an extension of the adoption to technologies related to the original information cascade. Table 2 details a follow-on Facebook ${ }^{\mathrm{TM}}$ communication after $\mathrm{BG}$ purchases the iPhone ${ }^{\mathrm{TM}}$. The discussion centres on software applications that run on the iPhone ${ }^{\mathrm{TM}}$

Note the lack of any specific information in the communications, or sharing of private information regarding the applications. The only information BG gains from the exchange are the applications that have been adopted and the number of individual units (friends) in her social network who have adopted the application. BG's decision to adopt appears to be based purely on previous adopters' behaviour.

Conceptually, BG is an early majority adopter, operating under a simple holistic rule that BG will adopt if BG's Facebook friends have adopted. This example demonstrates how an information cascade for the iPhone ${ }^{\mathrm{TM}}$ generates purchase activity irrespective of technical or private information.

\subsubsection{Example 4}

Fad-like iPhone ${ }^{\mathrm{TM}}$ adoption is not just a US phenomenon. In order to illustrate the international prominence of the herd mentality, we next provide micro level illustrations of the phone's adoption in China, Apple's second largest market after the USA (Satariano, 2012). China is an ideal choice for this analysis as the device was not released until well after it became available in other parts of the world so that the adoption process could be monitored up to and at its commencement. Additionally, previous research has shown that the Chinese consumer is susceptible to normative influences without in-depth knowledge of products which are preconditions for fad-like adoption (Zhan and He, 2012). This provides a good test of the theory, as both technical information and knowledge of fad adoption rates in other parts of the world are available to this new market prior to the first sale day.

To capture the adoption criteria of early Chinese adopters, we examined user postings in Chinese iPhone $^{\mathrm{TM}}$ blogs to locate illustrations of individual fad-like adoption behaviour. Web searching has been documented as a good indicator of planned and actual technology adoption activity (Jun, 2012). The blogs studied were set up to facilitate consumer discussions of smart phone adoption, particularly the iPhone ${ }^{\mathrm{TM}}$, enabling our analysis of the reasoning process of its first adopters in this new market.

Through an extensive search of the internet, we identified five Chinese-language blogs dedicated to discussions of the iPhone ${ }^{\mathrm{TM}}$, such as Dospy and Weiphone. A native Chinese speaking research associate was trained to read through all blog entries from a four week period after the January 13, 2012 release of the iPhone ${ }^{\mathrm{TM}} 4 \mathrm{~S}$ in Beijing. Blog entries containing evidence of adoption plans and reasoning were then captured for further analysis. Due to the large number and content variability of blog entries, analysis sought to identify entries that clearly indicate fad-like adoption. Entries selected would be devoid of private information use in the adoption decision, relying solely on indicators relating to the adopters knowledge of others adopting. Therefore we looked for terms relating to peer pressure, fashion, and trend. We identified over 30 entries indicative of solely fad-like behaviour for adopting the iPhone ${ }^{\mathrm{TM}}$. A sample of entries are included below (all entries were translated to English by a bi-lingual team-member). 
- ...I am jealous with people who are using iPhone when I don't have one.

- ... follow the fashion trend and show off, I don't have to explain more!

- ... just satisfied the psychological needs and I don't have the real purpose to have it...

- Actually, I bought an iPhone because it is expensive and famous.

- I got iPhone 4 because it is expensive and the apple brand.

- The reason I bought an iPhone is purely because I was curious why so many people love iPhone...

- I don't feel right when people are showing off their iPhone, so I just bought it.

- To tell you the truth, I just want to show off.

- I agree that people buy an iPhone because of face.

- ...the main reason is that I could keep my face and earn some confidence.

- Lots of people around me are using iPhone. If I don't use an iPhone, I am not part of the group but a stranger. So, finally I got an iPhone. Just to follow the fashion.

The authors then coded the quotes to detect patterns in individual units' adoption criteria. Three main reasons for adoption of the iPhone ${ }^{\mathrm{TM}}$ emerge in these quotes, namely,

1 following a fashion trend

2 showing off

3 saving face.

Each is based on interaction with other individuals and does not include consideration of the technical, functional, cost, or usability of the iPhone ${ }^{\mathrm{TM}}$. Additionally the entries indicate a status conveyed to the individual owning an iPhone ${ }^{\mathrm{TM}}$, suggesting a reciprocal relationship where fad-like adoption occurs not simply based on the number of previous adopters but an additional factor relating to self-esteem or social status.

\section{Conclusions}

Fad-like technology adoption refers to the rapid adoption of technology by individual units that act in what can appear to be an irrational manner. Rather than deciding to adopt technology based on a product's utility, quality and functionality, they adopt based on the number of individual units previously acquiring the technology. These individual units each have an adoption threshold. This threshold reflects the number of individual units that must have previously adopted the technology before individuals choose to adopt the technology based only on the number of previous adopters and no other information. When this occurs an information cascade is said to have started.

These observations are in line with previous research suggesting that new technology bundles together forming a set of ideas and knowledge that creates a new fashion to introduce to the adopter (Newell et al., 2000). Companies bundle and circulate new technology information to meet individual unit expectations within a social network. 
Combining this pattern of behaviour with the leading theory of the technology adoption lifecycle (Rogers, 1962), we show how early adopters of technology act as individuals and make the decision to adopt the technology based on rational decision processes. In the middle stages of the adoption lifecycle, when an information cascade is present, the individual units act in a holistic manner following an adoption rule based on adopter thresholds. In the final stages of the lifecycle the individual units act as individuals, returning to individualistic behaviour either by breaking from the cascade or finally making the decision to adopt. This is demonstrated with two examples at the product level, extending the applicability of the adoption lifecycle model beyond the product class level of analysis of many prior studies.

As shown with the introduction of the iPhone ${ }^{\mathrm{TM}}$, Apple has done a masterful job controlling this type of social action. Relying on extensive pre-product introduction marketing Apple moves device sales almost instantly through the individualist behaviour into the holistic fad-like adoption behaviour garnering massive sales with each new model release.

Although a single product (iPhone ${ }^{\mathrm{TM}}$ ) cannot be generalised to all information technologies, information technology research has a long established history of studying fads and fashions (Banville and Landry, 1989; Baskerville and Myers, 2009; Gregor and Jones, 2007) that itself provides historical validation that this is not a unique phenomenon. What is unique here is the attempt to discover and explain the patterns of behaviour behind the adoption of a technology fad, by combining several theories of innovation adoption patterns with macro (holistic) and micro (individualistic) behaviour to provide a better understanding of consumer technology adoption behaviour.

\subsection{Contributions to practice}

We make two important recommendations for companies releasing new technologies. First, during early introduction of a product it is essential to target the needs and expectations of the individual units most likely to adopt the technology. For example, Apple introduced a 90 second promotional video of the SIRI iPhone4S voice interface prior to the device introduction with the intent of enticing the innovator and early adopters to pre-order the phone (Bedigian, 2012). Apple knew these units would require private information to make the decision and would not adopt without that information. Apple provides this private information through the promotional video.

Second, as adoption of the technology begins, the company must ensure that individual units are aware of each other's actions. It is important to invest time and effort, early on, to move information on adoption rates out into the open so that an information cascade can commence. Consumer communications regarding a new product tends to increase imitation tendencies (Chung, 2011). Individual units need to know that other units are adopting, so the company must make this information available through press releases, reviews, tweets, blogs, or whatever medium is applicable.

\subsection{Future research directions}

Although the view of fad-like technology adoption as individual and holistic social behaviours is compelling, additional research requires extension beyond the single product or series of releases. The current work only looks at one technology's fad-like adoption. A thorough understanding of true fad-like behaviour calls for more detailed 
analysis across both competing products (e.g., other vendors' smart phones) and similar technologies (e.g., the iTouch ${ }^{\mathrm{TM}}$ and $\mathrm{iPad}^{\mathrm{TM}}$ ) alongside their own competitors. The impact of technology hype that precedes product releases by leading vendors such as Apple or Google also complicates the model presented (Hedman and Gimpel, 2010).

Releases of similar fad-embraced products may lead to 'cannibalisation' of other product line sales, or conversely an increase in related sales due to a 'halo' effect, both of which have been argued for in the trade press (Keizer, 2010a, 2010b, 2011). Relative to the case reported here, the impact of the release of the $\mathrm{iPad}^{\mathrm{TM}}$ on the iPhone ${ }^{\mathrm{TM}}$ would be a fruitful direction of study, as would analysis of the timing and interactions of their adoption cycles. What happens to the fad cycle or fashion appeal when production backlogs interfere with shipments to meet demand, as was the case when the $\mathrm{iPad}^{\mathrm{TM}}$ suffered from the 'mother of all backlogs' (Keizer, 2011)? Since analysis of these behaviours requires monitoring adoption activity in 'real-time', future analysis lends itself to longitudinal multi-case studies. The complexity of multiple, overlapping and competing product releases should lead to new or extended theoretical considerations.

Additionally we acknowledge that there are numerous other factors, aside from fad-like behaviours, that contribute to technology adoption. What is clear is that fad-like technology adoption does occur and is potentially a significant component of any technology adoption. An understanding of micro and macro fad-like technology adoption behaviours has become necessary to completely understand technology adoption.

\section{Acknowledgements}

The authors would like to thank Dr. Axel Seeman for his insights, reviews and support and Shuting Zheng for her tireless work examining and translating Chinese blog entries. This work was supported under NSF grant 0534877 . Parts of this paper were presented at AMCIS 2011 (Tomasino, 2010).

\section{References}

Abrahamson, E. (1991) 'Managerial fads and fashions: the diffusion and rejection of innovations', Academy of Management. The Academy of Management Review, Vol. 16, No. 3, p.586.

Abrahamson, E. and Rosenkopf, L. (1997) 'Social network effects on the extent of innovation diffusion: a computer simulation', Organization Science, Vol. 8, No. 3, pp.289-309.

Abrahamson, E. and Rosenkopf-Bartner, L. (1990) 'When do bandwagon diffusions roll? How far do they go? And when do they roll backwards?: A computer simulation', Academy of Management Best Papers Proceedings, pp.155-159.

Apple Inc. (2008) Form 10k: Annual Report Pursuant to Section 13 or 15(d) of the Securities Exchange Act of 1934, Washington, D.C.

Arruda-Filho, E.J.M., Cabusas, J.A. and Dholakia, N. (2010) 'Social behavior and brand devotion among iPhone innovators', International Journal of Information Management, Vol. 30, No. 6, pp.475-480.

Banker, R.D. and Kauffman, R.J. (1988) 'Strategic contributions of information technology: an empirical study of Atm networks', paper presented at the Ninth International Conference on Information Systems, Minneapolis, Minnesota.

Banville, C. and Landry, M. (1989) 'Can the field of MIS be disciplined?', Communications of the $A C M$, Vol. 32, No. 1, pp.48-60. 
Baskerville, R.L. and Myers, M.D. (2009) 'Fashion waves in information systems research and practice', MIS Quarterly, Vol. 33, No. 4, pp.647-662.

Bedigian, L. (2012) What Do the iPhone 4S Sales Figures Tell Us About Consumers? [online] http://www.forbes.com/sites/benzingainsights/2011/10/17/what-do-the-iphone-4s-salesfigures-tell-us-about-consumers/ (accessed 15 July 2012).

Beech/Chengdu, H. (2012) 'The cult of Apple in China', Time, p.180.

Beni, G. and Wang, J. (1989) 'Swarm intelligence in cellular robotic systems', Proceedings of NATO Advanced Workshop on Robots and Biological Systems, Vol. 102, pp.703-712.

Bikhchandani, S., Hirshleifer, D. and Welch, I. (1992) 'A theory of fads, fashion, custom, and cultural change as informational cascades', The Journal of Political Economy, Vol. 100, No. 5, pp.992-1026.

Block, M. (2007) iPhone Frenzy Starts Early in Manhattan [online] http://www.npr.org/templates/story/story.php?storyId=11433249 (accessed 27 February 2010).

Chung, J. (2011) 'Investigating the roles of online buzz for new product diffusion and its cross-country dynamics', Journal of Business Research, Vol. 64, No. 11, pp.1183-1189.

Demirci, A. and Ersoy, N. (2008) 'Technology readiness for innovative high-tech products: how consumers perceive and adopt new technologies', The Business Review, Vol. 11, No. 1, p.302, Cambridge.

DeToro, I. and McCabe, T. (1997) 'How to stay flexible and elude fads', Quality Progress, Vol. 30, No. 3, p. 55 .

Durkheim, E. (1938) 'Social facts, the rules of sociological method', in Martin, M. and McIntyre, L.C. (Eds.): Readings in the Philosophy of Social Science, pp.433-440, The MIT Press, Cambridge, Massachusetts.

Fichman, R.G. (2004) 'Going beyond the dominant paradigm for information technology innovation research: emerging concepts and methods', Journal of the Association of Infomration Systems, Vol. 5, No. 8, pp.314-355.

Gale, D. and Kariv, S. (2003) 'Bayesian learning in social networks', Games and Economic Behavior, Vol. 45, No. 2, pp.329-346.

Gibson, R.M. and Höglund, J. (1992) 'Copying and sexual selection', Trends in Ecology \& Evolution, Vol. 7, No. 7, pp.229-232.

Gilbert, M. (1990) Concerning Individualism Versus Holism On Social Facts, pp.427-431, Routledge Press, London.

Graham, J. (2010a) ‘Apple iPhone 4 flies off the shelf on first day of sales', USA Today [online] http://www.usatoday.com/tech/products/2010-06-25-iphone25_ST_N.htm (accessed 20 January 2012).

Graham, J. (2010b) ‘Apple sells 1.7M iPhone 4s in 3 days for its best product launch', USA Today [online] http://www.usatoday.com/tech/wireless/phones/2010-06-28-iphone-sales_N.htm (accessed 20 January 2012).

Gregor, S. and Jones, D. (2007) 'The anatomy of a design theory', Journal of the Association for Information Systems, Vol. 8, No. 5, pp.312-335.

Hedman, J. and Gimpel, G. (2010) 'The adoption of hyped technologies: a qualitative study', Information Technology and Management, Vol. 11, No. 4, p.161.

Hollis, M. (1934) The Philosophy of Social Science: An Introduction, 1994 ed., Cambridge University Press, Cambridge.

Jun, S-P. (2012) 'A comparative study of hype cycles among actors within the socio-technical system: with a focus on the case study of hybrid cars', Technology Forecasting \& Social Change, Vol. 79, No. 8, DOI:10.1016/j.techfore.2012.04.019. 
Keizer, G. (2010a) 'iPad 'halo' effect pushes Mac sales, use, ChangeWave says', ComputerWorld [online]

http://www.computerworld.com/s/article/9177090/iPad_halo_effect_pushes_Mac_sales_use_ ChangeWave_says (accessed 20 January 2012).

Keizer, G. (2010b) 'iPad halo effect brightens iPhone prospects', Computerworld [online] http://www.computerworld.com/s/article/9180466/iPad_halo_effect_brightens_iPhone_prospe cts (accessed 20 January 2012).

Keizer, G. (2011) 'Apple trumpets iPad cannibalization', Computerworld [online] http://www.computerworld.com/s/article/print/9205542/Apple_trumpets_iPad_cannibalization ?taxonomyName=Macintosh\&taxonomyId=163 (accessed 20 January 2012).

Kincaid, H. (1986) 'Reduction, explanation, and individualism', Philosophy of Science, Vol. 53, No. 4, pp.492-513.

Krazit, T. (2008) 'The iPhone, one year later', CNET News/Apple [online] http://news.cnet.com/8301-13579_3-9977572-37.html (accessed 20 January 2012).

Kunz, W., Schmitt, B. and Meyer, A. (2011) 'How does perceived firm innovativeness affect the consumer?', Journal of Business Research, Vol. 64, No. 8, pp.816-822.

Li, H., Dou, W., Wang, G. and Zhou, N. (2008) 'The effect of agency creativity on campaign outcomes', Journal of Advertising, Vol. 37, No. 4, pp.109-120.

Miller, D. and Hartwick, J. (2002) 'Spotting management fads', Harvard Business Review, Vol. 80, No. 10, pp.26-27.

Murphy, D. (2008) 'What the iPhone could teach auto industry about winning consumers', Advertising Age, Vol. 79, No. 28, p.6.

Needle, D. (2009) iPhone Marketing Guru Looks Back [online] http://itmanagement.earthweb.com/mowi/article.php/3838926/iPhone-Marketing-Guru-LooksBack.htm (accessed 20 January 2012).

Newell, S., Swan, J.A. and Galliers, R.D. (2000) 'A knowledge-focused perspective on the diffusion and adoption of complex information technologies: the BPR example', Information Systems Journal, Vol. 10, No. 3, pp.239-259.

Peters, O. (2009) 'A social cognitive perspective on mobile communication technology use and adoption', Social Science Computer Review, Vol. 27, No. 1, pp.76-95.

Ramiller, N., Swanson, E.B. and Wang, P. (2008) 'Research directions in information systems: toward and institutional ecology', Journal of the Association for Information Systems, Vol. 9, No. 1, pp.1-22.

Rogers, E.M. (1962) Diffusion of Innovations, The Free Press A Division of Simon \& Schuster Inc., New York.

Satariano, A. (2012) 'Apple chasing Asia sales says next iPad arrive in China', Bloomberg News [online] http://www.businessweek.com/news/2012-07-10/apple-says-next-ipad-tablet-willarrive-in-china-on-july-20 (accessed 16 July 2012).

Schramm, M. (2009) Tracking the iPhone Hype Generator [online] http://www.tuaw/.com/2009/02/18/tracking-the-iphone-hype-generator (accessed 20 January 2012).

Song, J. and Walden, E. (2003) 'Consumer behavior in the adoption of peer-to-peer technologies: an empirical examination of information cascades and network externalities', paper presented at the AMCIS 2003 Proceedings, paper 231.

Teo, H.H., Wei, K.K. and Benbasat, I. (2003) 'Predicting intention to adopt interorganizational linkages: an institutional perspective', MIS Quarterly, Vol. 27, No. 1, pp.19-49.

Tomasino, A. (2010) 'Fad-like technology adoption as a social action', 16th Americas Conference on Information Systems, Lima, Peru, paper 450 [online] http://aisel.aisnet.org/amcis2010/450.

Trotter, W. (1917) Instincts of the Herd in Peace and War, The Keynes Press, Cambridge, England. 
Tscherning, H. and Mathiassen, L. (2010) 'Early adoption of mobile devices-a social network perspective', JITTA: Journal of Information Technology Theory and Application, Vol. 11, No. 1, pp.23-41.

Valente, T.W. (1996) 'Social network thresholds in the diffusion of innovations', Social Networks, Vol. 18, No. 1, pp.69-89.

Walden, E. and Browne, G. (2009) 'Sequential adoption theory: a theory for understanding herding behavior in early adoption of novel technologies', Journal of the Association for Information Systems, Vol. 10, No. 1, pp.31-62.

Wang, P. (2010) 'Chasing the hottest IT: effects of information technology fashion on organizations', MIS Quarterly, Vol. 34, No. 1, pp.63-85.

Wang, P. and Ramiller, N.C. (2009) 'Community learning in information technology innovation', MIS Quarterly, Vol. 33, No. 4, pp.709-734.

Watkins, J.W.N. (1957) 'Historical explanation in the social sciences', The British Journal for the Philosophy of Science, Vol. 8, No. 30, pp.104-117.

Zhan, L. and He, Y. (2012) 'Understanding luxury consumption in China: consumer perceptions of best-known brands', Journal of Business Research, Vol. 65, No. 10, pp.1452-1460.

\section{Notes}

1 This paper focuses on technology adoption and does not extend its analysis to de-adoption. 